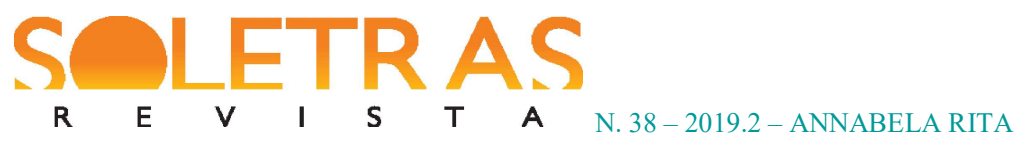

\title{
Rui Nunes ao espelho da Europa
}

Annabela Rita ${ }^{1}$

Resumo: Este trabalho visa a analisar o modo como Rui Nunes equaciona, na sua ficção, as relações entre vida e morte, através da mediação da dor, da doença, da senescência, da História colectiva e da biografia individual. Na estética do autor, a autorrepresentação desenvolve-se como reflexo ampliado de uma esfumada representação colectiva da Europa novecentista.

Palavras-chave: Morte. Vida. Dor. Mal. História.

George Steiner disse certa vez que o privilégio de Voltaire, Diderot, Rousseau, Holbach, Condorcet /.../ era sua ignorância: eles não sabiam o que sabemos e não podemos esquecer. A descendência da "Nova Jerusalém" de Isaias - relutantemente e não sem resistência - do futuro paradisíaco, fará isso a partir de Auschwitz, Kolyma e Hiroshima. Tudo isso foi fruto do cultivo entusiasmado e engenhoso do "nosso jardim".

Com as opções disponíveis entre ofertas de Tempo desacreditadas, cada qual carregando sua parte de horror, o fenômeno da "fadiga da imaginação", a exaustão de opções, emerge. A aproximação do fim dos tempos pode ser ilógica, mas por certo não é inesperada.

Zygmunt Bauman

A face do Anjo da História está voltada para o passado. Onde nós percebíamos uma cadeia de eventos, ele vê uma catástrofe única que continua empilhando destroços e jogando-os diante dos seus pés. $\mathrm{O}$ anjo gostaria de ficar, acordar os mortos, e tornar inteiro o que foi esmagado. Mas uma tempestade está soprando do paraíso; o anjo ficou preso em suas asas com tal violência que não pode mais fechá-las. Essa tempestade o impulsiona irresistivelmente em direção ao futuro, para o qual ele dá as costas, enquanto a pilha de escombros cresce, diante dele, rumo ao céu. A tempestade é o que chamamos progresso.

Walter Benjamin

\footnotetext{
${ }^{1}$ Doutorada e com Agregação e dois pós-doutoramentos em Literatura, é professora e Directora de Licenciatura na Faculdade de Letras da Universidade de Lisboa. Presidente / Academia Lusófona Luís de Camões | Instituto Fernando Pessoa | Assembleia Geral da CompaRes, Coordenadora/ CLEPUL, Directora/ Associação Portuguesa de Escritores | Observatório da Língua Portuguesa | Sociedade Histórica da Independência de Portugal. Membro de instituições científicas e culturais nacionais (Grémio Literário, Sociedade de Geografia de Lisboa, etc.) e estrangeiras (CREPAL - Centre de Recherche sur les Pays Lusophones Centre de Recherche sur les Pays Lusophones/Sorbonne e outros), integrando diversos Conselhos Científicos de revistas e de projectos. E-mail: annabela.rita@gmail.com. (1) https://orcid.org/0000-0002-1541-3006
} 


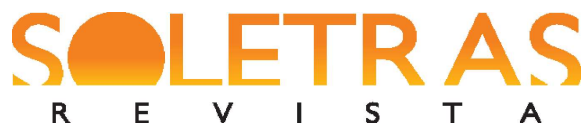

A Europa tende a projectar-se em algumas figuras maiores: Prometeu, Ulisses, Édipo e Fausto. Heráldica de um imaginário que a noite vem sombreando, numa cedência do élan construtivo, empreendedor e luminoso ao entristecido, enlutado e desanimado sentimento que Albrecht Dürer configurou em Melancolia I(1514), de uma série crepuscular com $O$ Cavaleiro, a Morte e o Diabo (1513) e São Jerónimo no seu Gabinete (1514). Um Anjo rodeado das insígnias do conhecimento e da técnica, desalentado de impotência, com um monstro alado ao fundo, desbobrando o título da gravura contra uma alvorada de utopia, quiçá, sinalizando algumas das ideias da De Occulta Philosophia, de Heinrich Cornelius Agrippa. Gravura da memória, da reflexão e do sentimento europeus. Gonçalo M. Tavares procurou analisar esse sentimento elencando constelações de tópicos associados que organizou em gráfico de ocorrências, simulando um longo e sincopado mural sugerido como itinerário percorrido pelas Artes, em particular a Literatura na sua Viagem fenoménica: Bloom n' Uma Viagem à Índia (2010), sobreimpressa em tantas outras, como a do seu homónimo de joyceana memória (Ulisses), de Ulisses na Odisseia homérica, a de Vasco da Gama n'Os Lusíadas camoneanos ou a de Harold Bloom n'O Cânone Ocidental (1994), todas diferentes, mas compondo, em diversidade tonal, epocal e autoral, um Crepúsculo dos Deuses a que Wagner (Der Ring des Nibelungen/O Anel do Nibelungo, 1869-74) não é alheio, insinuando nesse título (o quarto do ciclo) uma espécie de apocalise (fim do mundo e sua revelação) anunciado no nórdico Ragnarök.

Com Rui Nunes, o Crepúsculo é já sem Deuses nem Anjos nem Anéis, sem transcendência. A dor é o início e o fim da História, o texto que se pode seguir, acompanhar, ler, mas, sob ele, precedendo-o já, dissimula-se um outro que o explica, justifica e em que ele se gera: o progresso triunfante do mal (doença, no sentido mais lato) e da morte. A ficção, na sua fragmentação de negra luminosidade, é a expressão da desordem e do caos a imporem-se a uma ordem ilusória e fugaz: a lei dominante do movimento e da vida é letal.

Na confluência das velhas tradições da Arte de Bem Morrer, da Vanitas e dos Memento Mori, e da moderna visão agónica que bebe no espanto e do horror do homem pela sua própria ultrapassagem dos limites do mal (desumanizante), mas também na busca de uma heráldica e de uma genealogia da expressão estética da modernidade nas suas diferentes práticas, Rui Nunes oferece-nos uma obra que tenho revisitado e que aqui lembro no que demonstra de trabalho poiético no folheio de uma memória canónica estética, configurando-se em 
fragmentária e ficcional autobiografia no espelho ${ }^{2}$ dessa memória que vai reconformando nos seus textos. ${ }^{3}$

N’Uma Viagem no Outono (2013), Rui Nunes visita o “Anjo da História” (Walter Benjamin), parecendo assinalar na tiragem simbolicamente reduzida, uma mensagem para uma fraternidade. Fratres de uma Europa mediterrânica, cujo sangue vertido na guerra tinge a fotografia da capa. Fratres de outras leituras: Uma viagem sentimental (1768), publicado um mês antes da morte de Laurence Sterne, tematizando as suas viagens marcadas pela tuberculose irredutível, parecem constituir-se como testamento e despedida autoral. Fratres de escutas: Winterreise (Viagem de Inverno, 1827), ciclo de 24 lieder $^{4}$ de Franz Schubert sobre poemas de Wilhelm Müller (1794 -1827) a que Andres Neuman dedicou um romance (Viajante do Século, 2009, Prémio Alfaguara e Prémio Nacional da Crítica), dando vida a vários dos seus personagens; O Viajante e a sua Sombra (Der Wanderer und sein Schatten, 1880), de Friedrich Nietzsche; tantas outras viagens de inverno (de Georges Perec, Helder Macedo, Luís Filipe Castro Mendes, Vincent Dieutre, etc.) ou de viagens, simplesmente (a mais longa e metamórfica tradição literária, barómetro dos movimentos da História).

$\mathrm{Na}$ capa do volume, o brilho do rio gelado, corte diagonal no tapete de flores de sangue, evoca a lâmina de uma faca implacável, instrumento dessa Dama Morte com quem a ficção nunesiana insinua dançar: ao longe, o barco de escritores da viagem de propaganda nazi, contemplando o postal preparado, ou a Theresienstadt, cidade artificial supostamente dedicada aos judeus (de acordo com o filme O Führer oferece uma cidade aos judeus ${ }^{5}$ ),

\footnotetext{
${ }^{2}$ A imagem do espelho é pregante na tradição da Arte de Bem Morrer: oSpeculum Humanae salvationis (espelho da salvação humana), do séc. XIV, de Vincent de Beauvais, uma das obras mais divulgadas no final da Idade Média, é dominado pela especularidade estrutural, confrontando cenas do Novo e do Antigo Testamento. Também a Biblia pauperum (Bíblia dos pobres) oferece a imagística cristológica como espelho pedagógico para compreensão de uma comunidade mais alargada.

${ }^{3}$ Esta reflexão continua trabalho anterior e consagra elementos da comunicação "Rui Nunes: figurações da morte" apresentada Rethinking Warfare, 9-10/Novembro/2012, na Universidade Fernando Pessoa.

${ }^{4}$ São eles: Gute Nacht (Boa Noite), Die Wetterfahne (O Catavento), Gefrorne Tränen (Lágrimas Congeladas), Erstarrung (Solidificação), Der Lindenbaum (A Tília), Wasserflut (Torrente de Água), Auf dem Flusse (Sob o Rio), Rückblick (Retrospectiva), Irrlicht (Fogo-fátuo), Rast (Descanso), Frülingstraum (Sonho de Primavera), Einsamkeit (Solidão), Die Post (O Correio), Der greise Kopf (A Cabeça Grisalha), Die Krähe (O Corvo), Letzte Hoffnung (Última Esperança), Im Dorfe (Na Aldeia), Der stürmische Morgen (A Manhã Tempestuosa), Täuschung (Engano), Der Wegweiser (O Sinal Indicador), Das Wirtshaus (A Estalagem), Mut (Coragem), Die Nebensonnen (Os Sóis Vizinhos) e Der Leiermann (O Homem do Realejo).

${ }^{5}$ Theresienstadt era passagem para Auschwitz, pelo que eram regulares as levas de prisioneiros que dali partiam de comboio com esse destino. No Outono de 1944, os nazis montaram uma operação de propaganda que iludiu representantes da Cruz Vermelha. A exibição do filme O Führer oferece uma cidade aos judeus (Der Führer schenkt den Juden eine Stadt, 1944), reforçou a ideia de que se trataria de uma urbe de intensa actividade musical e, em geral, artística. no campo tinha lugar de relevo...
} 


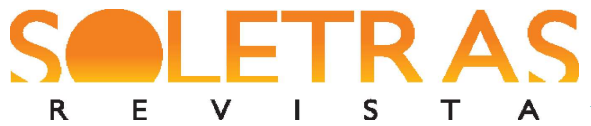

N. 38 - 2019.2 - ANNABELA RITA

embebida em arte (convenceu os representantes da Cruz Vermelha Internacional que a visitaram em 1944), e que, na realidade, foi aparelho de extermínio. A música tocada na fantasmagoria da ignorância: a dos que tocavam sem saberem se continuariam vivos para o concerto seguinte e a dos que ouviam no desconhecimento de se lá chegariam também, fraternidade eminentemente trágicas. As crianças tinham como tema de desenho "Desenha o que vês!"... esse traço projecta-se, agora, no da ficção nunesiana.

Em Nocturno Europeu (2014), Rui Nunes percorre, emocionadamente, essa fraternidade europeia, onde as sombras do crepúsculo ocultam os vestígios de uma convivência sangrentadesde as origens, latente, iminente ("A mão do cego lê na proximidade da pedra. / Ou de outra mão. / A mão do cego não acolhe, pressente. / Sinuosa irrespirável solidão.").

O ciclo da casa individual de Rui Nunes inscreve-se, assim, no ciclo da casa colectiva, europeia. Por ambos dobra um Réquiem: pelo passado morto e fantasmaticamente presente; pelo futuro anunciado, pelos que morreram e pelos que morrerão, sem missa, sem sepultura, sem lugar. Circunscrevendo-nos ao ciclo da casa individual de Rui Nunes, observemos que ficção nela e dela se esboça.

No centro da obra de Rui Nunes, desdobra-se um políptico cuja dimensão poiética se evidencia progressivamente, afirmando-se quase como sua espinha dorsal (ou pontos luminosos dela): Osculatriz (1992), Que sinos dobram por aqueles que morrem como gado? (1995), Grito (1997) e O Choro É Um Lugar Incerto $(2005)^{6}$. Outras obras permanecem sob a velatura que margina esses pontos, mas sob o signo da morte que emerge, se impõe e domina. A escrita coreografa-a, desenhando-lhe a cena e a história, transfigurando-a. Em curso na vida, em guerra com ela.

O último, O Choro É Um Lugar Incerto, encerra e ilumina esse "ciclo da casa", sendo esta, aliás, enunciada em subtítulo na "Segunda Parte": "os habitantes da casa: luz, palavra, segredo"(Nunes, 2005, p. 47), do volume: Osculatriz é a linha que contorna essa "casa" ficcional e íntima cindida pela bipolaridade de Que sinos dobram por aqueles que morrem como gado? (diário vs. polifonia dramática), agonicamente estilhaçada em Grito e reconduzida da solidão marginalizante à tradição estética em O Choro éum Lugar Incerto, que

\footnotetext{
${ }^{6}$ Rui Nunes. O Choro é um Lugar Incerto, Lisboa, Relógio d'Água, 2005. Quase todas as citações são retiradas desta edição e, por comodidade, localizadas no corpo do texto; quando isso não acontece, a referência é dada em rodapé.
} 


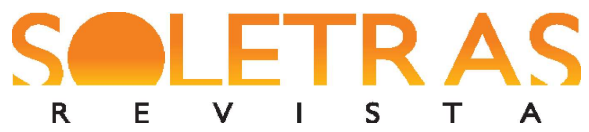

o sela e lhe elabora a heráldica. Os três últimos transformam, mesmo, em linha fúnebre essa osculatriz de dor tangencial à morte: o diário da morte em si (Que sinos dobram por aqueles que morrem como gado?) conduz à sua figuração numa múmia (Grito) ${ }^{7}$ e esta à sua degradação na caveira (O Choro é um Lugar Incerto).

Depois, A Boca na Cinza (2003), A Mão do Oleiro (2011) conduzem-nos ao trabalho de escrita espelhado em Barro (2012): o autor-oleiro revisita a memória dos momentos em que as coordenadas da vida e da morte se cruzaram ou se tangenciaram, figurando-lhes a dor e a agonia, esclarecendo-os na letra, iluminando-os com luz negra, fúnebre, sombria.

Esse Lugar Incerto, alfa e ómega da escrita, do signo, fantasmático por excelência, indizível e incognoscível, insinua o deslizamento do ficcional para essa outra dimensão onde a suspeita impera e os contornos se mesclam: a loucura, ou a clarividência que lhe é tangencial. Erasmiana alusão tingindo a modernidade na génese do romanesco, cervantino, quixotesco ${ }^{8}$. Ou consciência da irremediável distância entre o signo e a sua referência, distância onde se digladiam a vida e a morte da imagem e de que se tece a sua dimensão estética.

Lugar Incerto de estranha geometria espacial: a sombra resulta da projecção de um obstáculo ao foco luminoso, silhueta bidimensional, invertida e proporcional à opacidade desse obstáculo, projecção desenvolvendo-se em exponencial amplificação (quiçá, também, multiplicação), a partir de um ponto comum. Luz e sombra, tridimensionalidade e bidimensionalidade, sobreposição e distanciamento, proporcionalidade e desproporcionalidade, semelhança e diferença, evidência e dissimulação, os contrários confrontam-se, enfrentam-se e evoluem, informando o signo da quarta dimensão e dissolvendo-o, por fim, no abismo do silêncio em que a derradeira brancura textual se verte.

Do primeiro ao último dos painéis do ciclo da casa, cada volume se sugere como uma espécie de corte epistemológico (plano interseccionante) de um cone perspectivante que converge para esse vértice onde o conjunto se cristaliza: um crescendo de circunscrição, reflexividade, concentração e síntese domina o conjunto: "Entre escarpas, no interior do pó,

\footnotetext{
${ }^{7}$ Se o título evoca incontornavelmente $O$ Grito (1893), de Edvard Munch, este sugere a imagem de uma múmia, o que parece justificar-se na própria génese do quadro: segundo Robert Rosenblum, a cabeça do quadro teria tido como modelo a da múmia peruana que está no Museu do Homem, em Paris (cf. Ulrich Bischoff. Munch, Lisboa, Taschen, s.d., p.53).

${ }^{8} \mathrm{Cf}$. Carlos Fuentes. "Le triomphe de l'imagination critique. A la louange du roman ", Le Monde Diplomatique (Décembre 2005): [http://www.monde-diplomatique.fr/2005/12/FUENTES/13007\#nb3].
} 


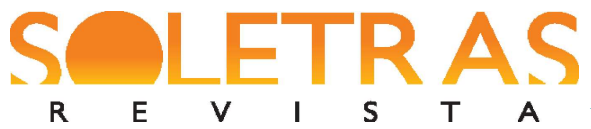

N. 38 - 2019.2 - ANNABELA RITA

um brilho de pó que o vento ora espalha, ora concentra. Só a fresta alberga a sombra: um vulto vira para nós a desolação" (NUNES, 2005, p. 40).

Assim, a "Segunda Parte" de O Choro é um Lugar Incerto mantém com o políptico uma relação reflexiva e de síntese, esclarecedora e museológica. Aí se apresentam "os habitantes da casa: luz, palavra, segredo", reduzindo à sua expressão mais elementar a matéria da escrita: a luz é a "arena" (NUNES, 2005, p. 39), onde se confrontam a palavra e o segredo e é o jogo entre luz e sombra (a sua ausência) que constitui a palavra em imagem e a enigmatiza, acabando por dissolvê-la no buraco negro do universo nunesiano que o poema "S/ Lugar", no final, representa e configura, além-túmulo de onde a voz autoral enuncia um ofício dos mortos: um "Requiem" (NUNES, 2005, p. 65) anunciado e iniciado (assumido, enfim) no "10 dia" do diário autoral de Que sinos dobram por aqueles que morrem como gado? (com a frase "let the perpetual light shine upon them" (NUNES, 1995, p. 8), um "Requiem" (Nunes, 2005, p. 65), que sintetiza o políptico, mas que também lhe sublinha o ritmo e a modalização. Concluindo o ciclo, a interrogação fantasmiza-lhe os vestígios, termina o ritual fúnebre e encerra o monumento:

\section{S/ Lugar}

Tudo isto é o sinal de uma perda.

Que fazer com todos estes sinais senão remetê-los como fantasmas para o corpo que abandonaram, que me abandonou?(NUNES, 2005, p. 85)

Da capa, uma fotografia de Paulo Nozolino impõe um exemplar da Vanitas reconduzindo a escrita de Rui Nunes à velha tradição da Ars Moriendi, mas reduzindo-a à sua expressão mais elementar: o crânio em decomposição e visto por trás, os ossos em cruz semidesfeita (dissolvendo a componente religiosa da via crucis da existência humana) e o jogo de luz e sombra. A perspectiva da caveira apaga-lhe o "rosto" e sugere o buraco como incisão produzida pelo choro (lacrimosa do Requiem ${ }^{10}$ ) que atravessa e fragmenta progressivamente o discurso do políptico: "um rosto cresce até à legibilidade, cresce e mostra o sofrimento, tão

\footnotetext{
${ }^{9}$ No Requiem em ré menor, KV 626, de Mozart, esta expressão repete-se no "Introitus" e no "Communio" e na Missa de Requiem de Verdi, repete-se no "Coro", no Communio, no Responsorium: "Et lux perpetua luceat eis." (E luz perpétua os ilumine) (cf. tradução em http://www.musicaeadoracao.com.br/obras/requiem_traducao.htm).

${ }^{10}$ Lacrimosa dies illa Dia de lágrimas será aquele/ Qua resurget ex favilla No qual os ressurgidos das cinzas/ Judicandus homo reus. Serão julgados como réus.// Huic ergo parce, Deus A este poupa, ó Deus/ Pie Jesu Domine Piedoso Senhor Jesus/Dona eis requiem, Amen. Dá-lhes repouso. Amém. (Requiem em ré menor, KV 626, de Mozart, cf. http://www.musicaeadoracao.com.br/obras/requiem_traducao.htm).
} 


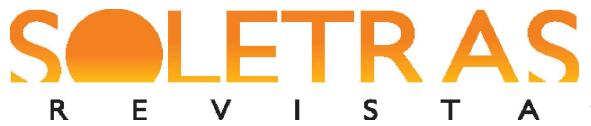

N. 38 - 2019.2 - ANNABELA RITA

intenso, que esbate cada linha numa doença da fronteira. A morte rodeia-o dos seus sinais: peso, mortalha, letras, números, porém ele parece dormir, no silêncio de um nome a apagarse. E, nesse sono, sonha a infância: /..." (NUNES, 2005,p. 29). É a vinculação da escritapranto ao sonho gerado na via da morte e por ela iconografado. Ars Moriendi.

O Choro é um Lugar Incerto surge, pois, como uma espécie de Livro da Revelação autoral que reordena, ilumina e redimensiona o percurso realizado. No fim, por fim, selado pela imagem que melhor o simboliza: o crânio fracturado e os ossos. À sua luz, a palavra, toda a escrita do autor, torna-se inscrição funerária, sinalização da morte $a$ vir e habitando a vida e a escrita.Revisito, então, esse político de que me tenho vindo a ocupar noutros textos, agora, sob a luz fúnebre deste Livro da Revelação ${ }^{11}$.

Se, em O choro é um Lugar Incerto, se enunciam os elementos do universo nunesiano ("luz, palavra, segredo"), a verdade é que a sua arquitectura se expõe no conjunto dos quadros que constituem a "casa". A sua história, ciclo de vida e morte da escrita nunesiana, representa-se no políptico e sintetiza-se em cada um dos seus painéis e, mais ainda, na "Primeira Parte" do livro, a que lhe dá o título, onde o trajecto se desenvolve em fantasmático diálogo com o de fotografias de Paulo Nozolino (evocadas em incipit, na pág. 29) ${ }^{12}$ e a partir de uma delas, do enigmático vértice criado pelo encontro de duas paredes e de um chão, centro geométrico para onde se dirige o indivíduo (de costas como o crânio da capa, cada um o negativo do outro) onde se projectam os sujeitos de escrita e o de leitura numa fusão que se renova no início da "Segunda Parte":

\author{
"Mauthausen \\ abre o livro, \\ relê em cada palavra a tua dor, \\ respira o pesadelo entre dois nomes, \\ ninguém sabe em que pausa se constrói a casa \\ nem quais os caminhos que a dispersam"(NUNES, 2005, p. 52)
}

11 Este ensaio continua uma reflexão que as obras de Rui Nunes já me mereceram, independentemente, em ensaios que reúno no volume II de No Fundo dos Espelhos (Edições Caixotim, Porto, 2006). Remeto, pois, para eles, essa observação mais casuística e esclarecedora desta minha leitura.

${ }^{12}$ O texto "O Choro é Sempre um Lugar Incerto", de Rui Nunes, foi escrito para acompanhar a exposição fotográfica Far Cry (Museu de Serralves, 2005), de Paulo Nozolino, e algumas dessas fotografias integram o volume. 


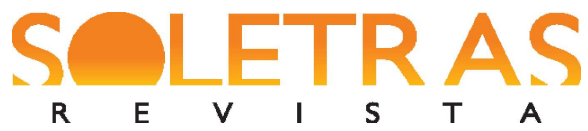

E, em contra-luz fantasmático, a exposição de Paulo Nozolino encenada em sombrios corredores, parece retomar o modelo dos corredores dos monumentos fúnebres egípcios, com os seus Livros dos Mortos pintados nas paredes, divididos entre a cartografia da vida e a da caminhada para o Além. Mas também faz evocar outras ficções e figurações dessa viagem para e pela morte, lugar incerto, tão obsessivamente cartografada e que autores como Dante Alighieri tanto celebraram.

O Choro é um Lugar Incerto gera-se, assim, num lugar incerto (anterior e preparatório da exposição) informado da incerteza de outros lugares (a desse Além sistematicamente recartografado nas obras que lhe são dedicadas), assumindo um deles como sua imagística simbólica (o itinerário fotográfico de Far Cry), expressão, figuração.

Depois, o ciclo individual em que o colectivo se manifesta cede ao colectivo em que o individual se exprime: "à espera da explosão"13 como a crisálida...

Nocturno Europeu (2014), A Crisálida (2016), Baixo Contínuo (2017), A Margem de Um Livro (2017), Lampedusa (2017) e Suite e Fúria (2018) compõem a cartografia do luto colectivo, da morte anunciada, pressentida e inscrita no tecido da existência de uma Europa em noturno, cartografia onde a mancha sanguínea evoca o horror da morte infligida, desumananizada, fantasmizada pelo nazismo, encarado, não só como "uma memória histórica", mas como "um perigo", "porque pode renascer sob outra forma" e "está a renascer"14. Na abertura de Suite e Fúria (2018)15, "Suíte e Fuga", enuncia-se, mesmo, lapidarmente, a hermenêutica do itinerário: "letra a letra, o som de uma arcaica máquina de morte". No final das “Anotações”, a bold, a frase será reescrita:

\section{"Letra a letra chega-se à palavra completa: à revelação" (NUNES, 2018, p. 92)}

Em entrevista recente, Rui Nunes afirma sobre a referência a Heraclito em Suite $e$ Fúria (2018):

É interessante como é que ele aparece. Eu estava a ler o seminário dado por Martin Heidegger e Eugen Fink sobre Heraclito. Heidegger fascina-me e repugna-me, simultaneamente, portanto tenho sentimentos muito fortes em relação à figura e ao pensamento. E depois havia todo aquele processo de

13 Em entrevista concedida a Hugo Pinto Santos em 16 de novembro de 2018. Disponível em: http://visao.sapo.pt/jornaldeletras/2016-04-28-Rui-Nunes---A-Europa-rente-ao-chao.

${ }^{14}$ Em entrevista concedida a Hugo Pinto Santos em 16 de novembro de 2018. Disponível em: https://www.publico.pt/2018/11/16/culturaipsilon/entrevista/rui-nunes-escrita-olhar-1850215\#gs.M6VPZWRz.

${ }^{15}$ Suite e Fúria, Lisboa, Relógio d’Água, 2018. 


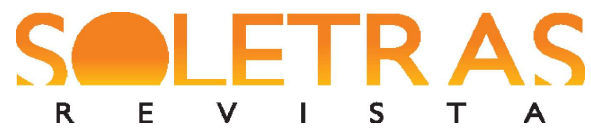

análise do texto de Heraclito, com a ultrapassagem do próprio texto e a criação de uma figura fantasmática, que é um outro Heraclito. Isso seduziu-me. Como sempre, eu ia escrevendo notas à margem, durante a minha leitura, e nessas notas começou a entrar o problema da criação de uma personagem. Isto é, de Heraclito enquanto personagem quase romanesca. E isso atirou-me para divagações de outra índole. Além disso, há em Heraclito uma coisa que me fascina, a relação com o tempo, com a mudança, o conflito, a guerra - e, de certo modo, tudo isso está presente no meu livro. Daí eu entender que seria interessante eu ter a matriz do próprio livro. Isto é, como é que ele surgiu a partir daquela leitura. Ao mesmo tempo, ia introduzindo alguns elementos da minha relação específica com o pensamento de Heidegger — e com a repulsa de muito daquilo que ele diz. ${ }^{16}$

E o noturno nunesiano ritma a revisitação das referências mais canónicas da identidade europeia, exactamente as que a dilaceraram entre Eros e Thanatos, o sublime e a distopia, os excessivos de sinal contrário: em Suíte e Fúria (2018), Ulisses, Penélope e Ítaca refractam-se metamorficamente na fluidez da memória colectiva aspirando e temendo o futuro...

Hoje, a violência já não está circunscrita aos territórios de caça, rodeados de arame electrificado. Coutadas. Há, por todo o lado, palavras de um sangue indiferente. E há o sangue.

A Crisálida (Lisboa: Relógio d'Água, 2016, p. 7)

Dies iræ, dies illa,

Solvet sæclum in favilla;

Teste David cum Sibylla.

Quantus tremor est futurus

Liber scriptus proferetur,

In quo totum continetur,

Wolfgang Amadeus Mozart

\section{Referências}

FUENTES, Carlos. Le triomphe de l'imagination critique. A la louange du roman. Le Monde Diplomatique (Décembre 2005):Disponível em: [http://www.monde-diplomatique.fr/2005/ 12/FUENTES/13007\#nb3].Acesso em: 10 de abr. 2019.

RITA, Annabela. No Fundo dos Espelhos. Em visita. Porto: Edições Caixotim, 2007.

${ }^{16}$ Em entrevista concedida a Hugo Pinto Santos em 16 de novembro de 2018. Disponível em: https://www.publico.pt/2018/11/16/culturaipsilon/entrevista/rui-nunes-escrita-olhar-1850215\#gs.M6VPZWRz 
Rui Nunes. Osculatriz, Lisboa, Relógio d'Água, 1992. 1995.

Que sinos dobram por aqueles que morrem como gado?, Lisboa, Relógio d'Água, . Grito, Lisboa, Relógio d'Água, 1997.

. O Choro é um Lugar Incerto,Lisboa, Relógio d’Água, 2005.

. Uma Viagem no Outono.Lisboa, Relógio d’Água, 2013.

\title{
Rui Nunes to the mirror of Europe
}

\begin{abstract}
This work aims to observe how Rui Nunes equates, in his fiction, the relations between life and death through the mediation of pain, illness, senescence, collective history and individual biography.In the aesthetics of the author, self-representation develops itselfas an extended reflection of a blurred collective representation of nineteenth-century Europe.
\end{abstract}

Keywords: Death. Life. Pain. Evil. History

Recebido em: 07 de maio de 2019.

Aceito em: 29 de maio de 2019. 